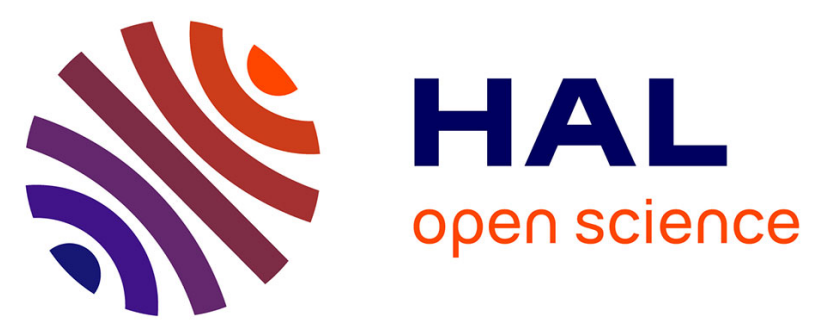

\title{
Simulation of electricity supply of an Atlantic island by offshore wind turbines and wave energy converters associated with a medium scale local energy storage
}

Aurélien Babarit, Hamid Ben Ahmed, Alain H. Clément, Vincent

Debusschere, Gaelle Duclos, Bernard Multon, Gaël Robin

\section{To cite this version:}

Aurélien Babarit, Hamid Ben Ahmed, Alain H. Clément, Vincent Debusschere, Gaelle Duclos, et al.. Simulation of electricity supply of an Atlantic island by offshore wind turbines and wave energy converters associated with a medium scale local energy storage. Renewable Energy, 2006, Vol.31 ( $\mathrm{n}^{\circ} 2$ ), pp.153-160. 10.1016/j.renene.2005.08.014 . hal-00676111

\section{HAL Id: hal-00676111 \\ https://hal.science/hal-00676111}

Submitted on 3 Mar 2012

HAL is a multi-disciplinary open access archive for the deposit and dissemination of scientific research documents, whether they are published or not. The documents may come from teaching and research institutions in France or abroad, or from public or private research centers.
L'archive ouverte pluridisciplinaire HAL, est destinée au dépôt et à la diffusion de documents scientifiques de niveau recherche, publiés ou non, émanant des établissements d'enseignement et de recherche français ou étrangers, des laboratoires publics ou privés. 


\title{
Simulation of electricity supply of an Atlantic island by offshore wind turbines and wave energy converters associated with a medium scale local energy storage
}

\author{
A. Babarit ${ }^{\mathrm{a}}$, H. BenHamed ${ }^{\mathrm{b}}$, A.H. Clément ${ }^{\mathrm{a}, *}$, \\ V. Debusschere ${ }^{\mathrm{b}}$, G. Duclos ${ }^{\mathrm{a}}$, B. Multon ${ }^{\mathrm{b}}$, G. Robin ${ }^{\mathrm{b}}$ \\ ${ }^{\mathrm{a}}$ LMF - (CNRS UMR6598) Ecole Centrale de Nantes - FRANCE \\ ${ }^{\mathrm{b}}$ SATIE - (CNRS UMR8029) Ecole Normale Supérieure de Cachan - FRANCE
}

\begin{abstract}
The problem of sizing an electricity storage for a 5000 inhabitants island supplied by both marine renewables (offshore wind and waves) and the mainland grid is addressed by a case study based on a full year resource and consumption data. Generators, transmission lines and battery storage are accounted for through basic simplified models while the focus is put on electricity import/export budget. Self sufficiency does not seem a reasonable goal to pursue, but partial autonomy provided by renewable sources and a medium size storage would probably be profitable to the island community.
\end{abstract}

Key words: Wave energy, offshore wind turbines, marine energy

\section{Introduction}

Marine renewables like tidal current and wave energy devices will come to the market in a near future in Europe [1], pushed by the commitment of most of these countries to supply a large part of their energy by renewables by 2010. For such intermittent sources the coupling with a local energy storage is often necessary in order to regulate the energy output flow. This is a routine procedure when one deals with small scale installations of a few $\mathrm{kW}$ like small wind turbines or photovoltaic cells installed to provide electricity in isolated

* Corresponding author.

Email address: Alain.Clement@ec-nantes.fr (A.H. Clément). 
sites. It is less common in large scale plants of dozens of MW which are most often connected to the main grid, acting then acts as a storage of infinite capacity.

In the present case study, we have evaluated by numerical simulations the benefit of coupling a medium scale electric storage to offshore wind turbines and wave energy converters, in order to supply electricity to a French island community. The case is virtual, no such project being planned today, but the simulations were performed by using real resource data (wind and waves) over a whole year (1999) and also the recorded data of the electricity demand of this island community.

In the study we systematically varied the storage capacity, and the power installed at sea, considering three cases: offshore wind farm only, wave energy only, or a mixed solution combining these two resources. From our results we could predict the resulting flux of electricity between the island and the mainland in the time-domain, on a one hour time step sampling. So, from this case study, we are now able to size the required electricity storage with respect to an energy management strategy which should be chosen by the island community as, for instance: self-sufficiency with regard to the utility network, or balancing the input and output electricity fluxes to a certain level, depending on economic parameters as $\mathrm{kWh}$ price, or any other choice of local energy management strategy.

\section{The data}

The data used for this study are related to the French island of Yeu, which is located $20 \mathrm{~km}$ off France west coast, near Nantes. The data shown in fig(1) are the actual wind and wave resource data over one full year (1999) on this site. Global electricity consumption of the island community are shown in fig.(4.top). These data sets were post processed to sample them on a one hour time step basis.

About 5000 persons live here all year long, but the island population increases by a factor 6 during summer holidays. That can explain why, the electricity demand is as important in summer and in April (Easter holiday) as in winter (due to house heating). During this sample year (1999), the average annual power demand was about $4.16 \mathrm{MW}$ and the peak power was recorded at 11.9 MW. This island is connected to the mainland grid by a three submarine cables rated 10MW each.

The top figure (1) shows the wind speed recorded at $55 \mathrm{~m}$ height. As expected in this country, the velocity of the wind is higher in autumn and winter than 
in summer. The year average velocity is about $5.84 \mathrm{~m} / \mathrm{s}$ and the maximal velocity is $24.3 \mathrm{~m} / \mathrm{s}$.

Medium and bottom figures (1) show respectively significant amplitude $\left(H_{s}\right)$ and period $\left(T_{s}\right)$ of the wave climate at a point few kilometers offshore Yeu island (data provided by LNHE). As expected, wave period and wave height are smaller in summer. As the wave power per meter of wave front can be estimated by: $\bar{P}=0.57 * H_{s}^{2} * T_{z} \mathrm{~kW} / \mathrm{m}$ (with $T_{z}=T_{s} / 1.2$ ), the wave energy resource is naturally smaller in summer. The yearly average incident wave power is evaluated at about $25.8 \mathrm{~kW} / \mathrm{m}$. For this site, the prevailing sea state is: $H s=1 \mathrm{~m}, T_{s}=10 \mathrm{~s}$ resulting in a mean incident power of $4.75 \mathrm{~kW} / \mathrm{m}$.

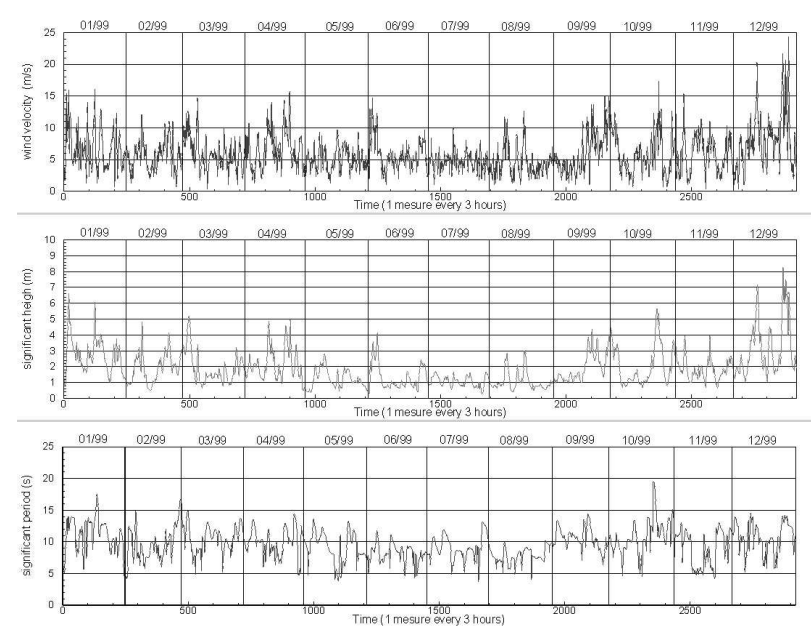

Fig. 1. Time evolution of wind velocity (top), significant wave height (middle) and significant wave period (bottom)

\section{$3 \quad$ Offshore energy generators}

Offshore farms of wind turbines and wave energy generators were considered here. They were modelled by simple basic input/output models which are described below. Losses in transmission lines, transients, hysteresis phenomena, ..., were not accounted for in this first simplified modelling of the global dynamics of this complex system.

\subsection{The wind turbine model}

In figure (2) the solid line shows the normalized power curve or a real device (from the manufacturer) and the dashed line is a simplified linear approximating power curve used in this study. When the wind velocity is lower than $4 \mathrm{~m} / \mathrm{s}$ 
the turbine is stopped and the power output is zero. For wind velocity greater than $25 \mathrm{~m} / \mathrm{s}$, the turbine is put in survival condition and the power is also set to zero. For velocity between $15 \mathrm{~m} / \mathrm{s}$ and $25 \mathrm{~m} / \mathrm{s}$, the output power is the rated power of the turbine. In the simulations we worked with a normalized power curve instead of a precise type of turbine, in order to vary easily the installed power of the virtual offshore park as a parameter. With this model of wind energy device and by using wind data depicted in previous section, a generic $10 \mathrm{MW}$ wind farm provides $21.52 \mathrm{GWh}$ on this site. The predicted power output of this farm over the full year is shown in the middle cell of figure 4 .

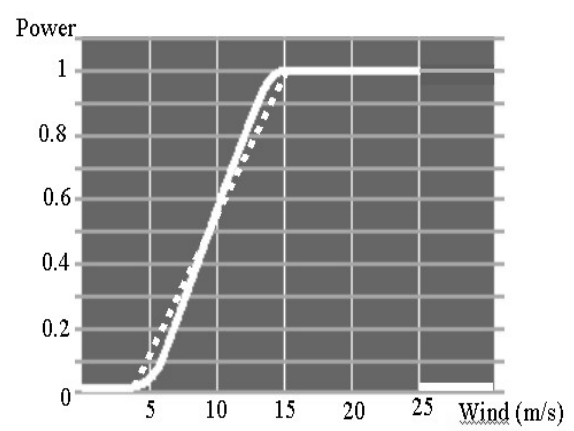

Fig. 2. Wind turbine: normalized power curve

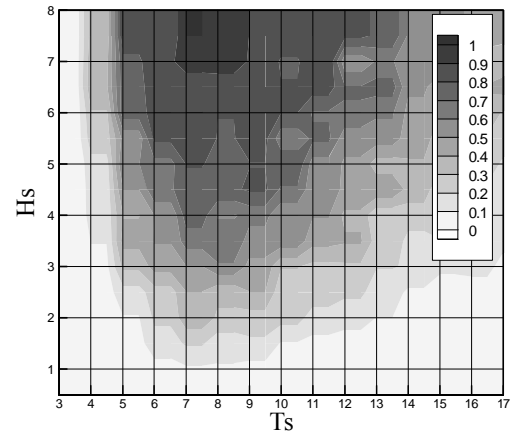

Fig. 3. wave energy device: mornalized power matrix.

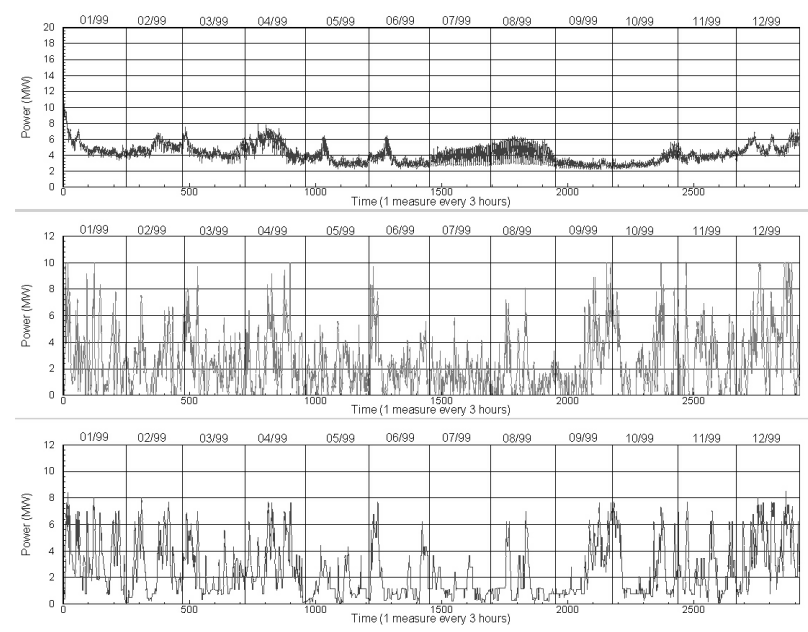

Fig. 4. (top) electricity comsumption; (middle) 10MW offshore wind farm production; (down) 10MW wave farm production.

\subsection{The wave energy device}

The wave energy device used here is a $250 \mathrm{~kW}$ version of the SEAREV floating system, currently under development at ECN [3]. As wind turbine power curves give the power output as a function of wind velocity, the average power 
matrix of a wave energy device (see Figure 3) allows to predict power output for each given sea state characterized basically by the two variables $\left(H_{s}, T_{s}\right)$ : significant wave height and period. The primary wave energy output being naturally fluctuating, we have to work here with average values. The average power output is indeed lower than the installed power, due to long periods of under rating running of the devices. To reduce the difference between average power and installed power, it is interesting to reduce the latter per module and multiply the number of modules, which automatically increases the capacity factor (i.e the annual energy production expressed in term of hours at rated output). The maximal average power that the current device can provide is about 0.9 times the installed power. For the prevailing sea state $(1,10)$, the normalized average power output is about 0.39 .

Applying this model of wave energy device to the wave data depicted in previous section, a 10MW wave farm would deliver $21.42 \mathrm{GWh}$ per year. The predicted power output over the year is shown in the bottom part of the figure 4 . So the global production efficiency is equivalent, at this site, for the wave farm as for the wind turbine farm.

\subsection{The electricity storage and transmission lines models}

In this study, we were primarily interested by the difference between the real dynamics of time domain consumption curves and offshore renewable energy production. So we keep a very basic modelling for the transmission and storage components. Unlike a previous more sophisticated approach to a similar problem in [2], we have considered here a "perfect" electricity storage model with no loss in input neither in output. This virtual electricity storage is indeed unrealistic, but because our goal here was only to compare the global efficiency of different configurations, we considered this assumption as valid. We also supposed that transmission lines are perfect (no loss).

\section{Results}

Three configurations were considered for the electricity supply of the island by the renewables: an offshore wind farm, a wave farm or a mix of those two sources. The installed power of each one and the storage capacity were the main parameters of the study. The complimentary part of electricity, when needed, is still provided by the utilitity grid from the mainland through the submarine cables. Left figure (5) shows the amount of energy exchanged yearly with the mainland: the island community imports energy when the offshore farms cannot provide enough energy, at the opposite when the amount of 
energy produced is larger than the demand, the community sells (export) energy in excess to the mainland.

Let us first consider a configuration without electricity storage, but with the constraint of no electricity supply breakdown during the full year.
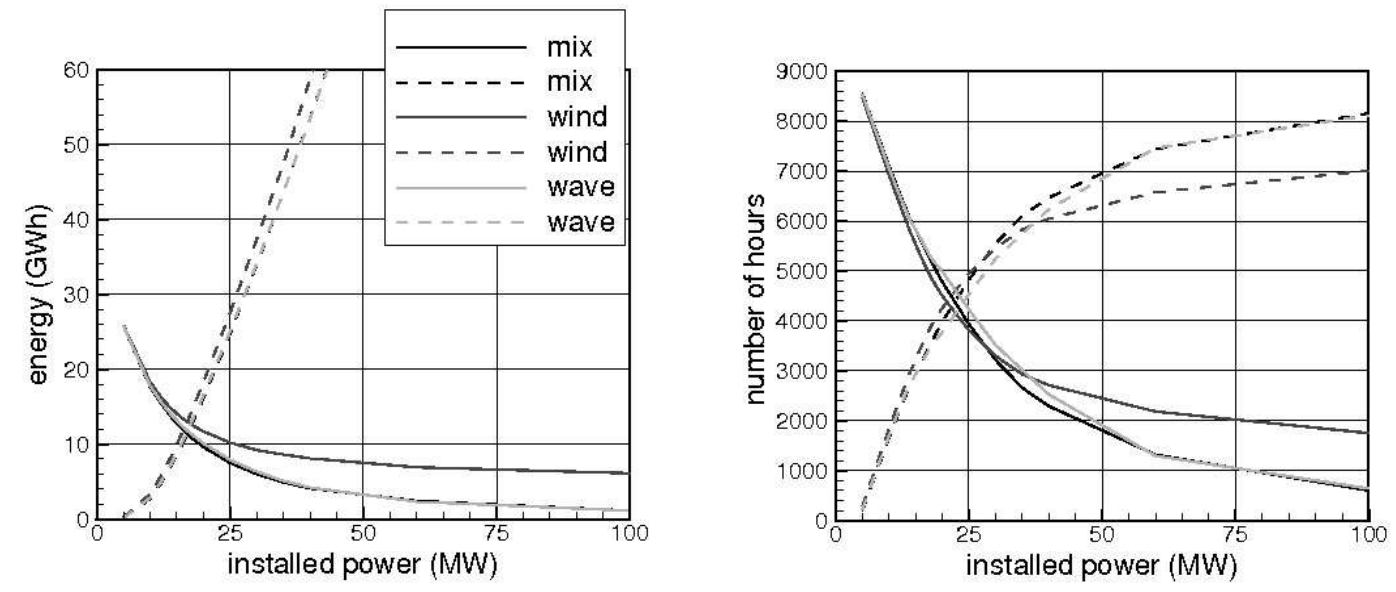

Fig. 5. Electricity exchange with mainland. solid lines : import (the community buy); dashed lines : export (the community sell)

We observe that curves corresponding to combined sources farm and wave farm are very close whatever the installed power. Whereas input and output energy fluxes are larger with wind generators, this difference increasing with installed power. Whatever the renewable source used, the amount of sold and bought energy are almost equal when the installed power is around 17MW. A $17 \mathrm{MW}$ wave farm and a 17MW wind farm provide respectively $36.41 \mathrm{GWh}$ and $36.58 \mathrm{GWh}$, which coincides with the energy consumed yearly (36.4GWh) by the island community.

The right part of figure (5) shows the number of hours spent by the community selling and buying electricity to the mainland grid. The curves cross around an installed power of $22 \mathrm{MW}$, which is a bit larger than the previous level of equal fluxes (17MW) for which energy importation duration is larger than exportation duration. This is a clearly consequence of the difference in the dynamics of electricity production from offshore sources and electricity consumption.

The asymptotic behavior of solid lines in fig.(5) shows that it would not be realistic, in terms of power installed offshore, to seek for complete self-sufficiency of the island; it would necessitates several hundred of MW offshore, to provide only 36 GWh per year for the community consumption, and the local grid would not be able to absorb the difference in excess.

Let us now introduce an ideal electricity storage on the island, with a ca- 
pacity to be determined by the numerical simulations. The amount of energy exchanged by the island with the mainland grid will indeed decrease when increasing this capacity, as shown for example in figure (6) corresponding to three configurations with $22 \mathrm{MW}$ installed offshore. For very small storage capacities, the wind farm curve slope is bigger than the two others, but when the capacity reaches $20 \mathrm{MWh}$, the exchanges of energy are quite similar whatever the kind of generators installed. The amount of imported energy with combined wind and wave sources always remains smaller than the two others individually, as expected, but only of a few percent. This is analysed as a consequence of the high correlation between offshore wind and wave energy resources. For large storage capacity, amounts of exchanged energy become very close all together. The difference between exported and imported amount of electricity is constant whatever the installed storage capacity, which is explained by the balance relation

$$
\text { production }+ \text { import }=\text { consumption }+ \text { export }
$$

implying that $[$ export - import $]=$ constant for a given production figure.

Whatever the kind of renewable farm used it seems quite impossible and unrealistic to obtain electrical self-sufficiency of Yeu Island, with a reasonable installed power. With a 20MW farm, the self-sufficiency would be obtained with $760 \mathrm{MWh}$ storage capacity (!). Nevertheless, and this is the most interesting conclusion here, it is easy for the community to reach a high level of autonomy with a large excess of electricity likely to be sold to the utility: for example with a $22 \mathrm{MW}$ farm (i.e: 5 times the averaged electrical power demand of the island and twice the peak demand) and a 50 MWh battery capacity (equivalent to 12 hours of averaged consumed power), the community will need to buy about 5 GWh (i.e: only $14 \%$ of its current yearly electrical consumption demand) and will be able to export three times as much as this amount of energy to the mainland network. Generalizing this approach by

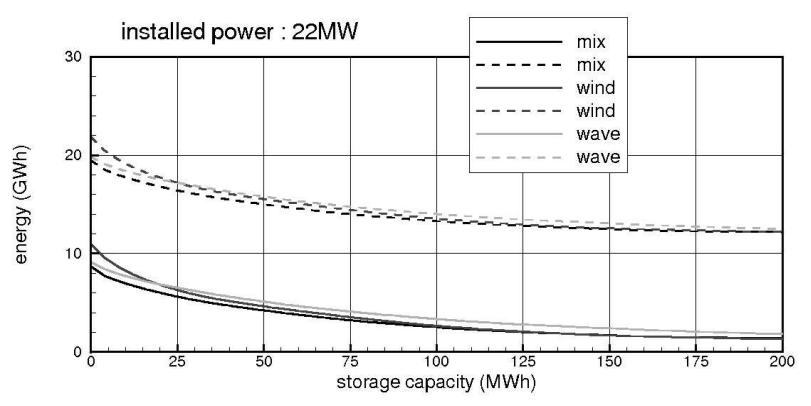

Fig. 6. annual imported and exported energy fluxes (legend same as in previous fig.)

varying the installed power of the offshore farms, either wind, waves or both, we were able to plot the curve in figure (7) showing the relation between the excess of electricity produced (i.e export - import) likely to be sold to the utility, versus the level of power installed offshore (reduced by the average power 
consumed by the island community).

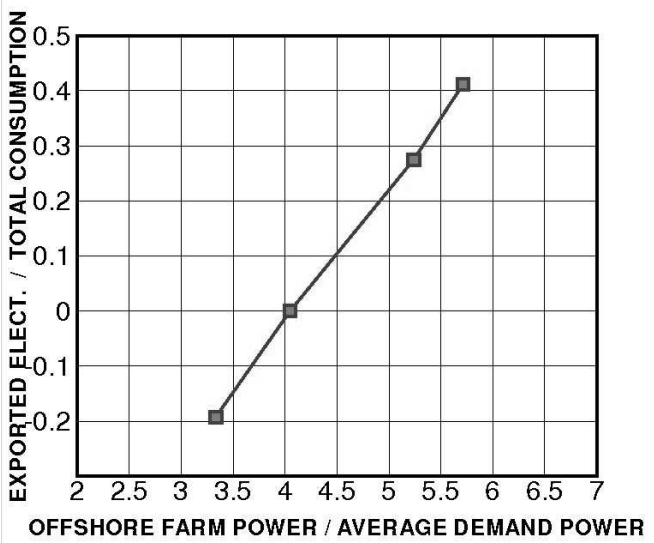

Fig. 7. excess production ratio versus installed offshore power ratio

The very high slope of this line must be interpreted as a favorable sign in favor of such an integrated solution, provided the electricity produced in excess can be exploited financially in order to balance the investment for the electrical storage equipment.

\section{Conclusion}

In this case study we have seen that the complementarity between offshore wind turbine and wave energy device is small due to the high correlation between these sources. The level of energy delivered annually are very similar for the same rated power installed at sea. This is encouraging since the model of wave energy power matrix used here is a very preliminary version of the device that we are still optimizing. A third solar source would have been welcome to cope with the summer demand due to tourist rush in this area. Such a complimentary study has been presented in 2004 [4].

It appears that full electrical self-sufficiency from offshore sources cannot be considered as a reasonable goal in the case of Yeu island. But we have shown that a high degree of energetic independence could be reached by associating to the offshore generators an electricity storage of reasonable capacity range. With such a configuration the ratio of exported over imported electricity could raise up to five or more. This should be accounted for in an economic study to be carried out now, but which was beyond the scope of the present study.

Acknowledgement: French utility EDF (LNHE) and Meteo-France are greatly acknowledged for having provided the data used in this study which was supported by the French Agency ADEME. 


\section{References}

[1] Clément, A. H., McCullen, P., Falcao, A., Fiorentino, A., Gardner, F., Hammarlund K., et al. Wave Energy in Europe: Current Status and Perspectives. Renewable \& Sustainable Energy Reviews 2002; 6,5: 405-431.

[2] Gergaud , O. " Modélisation énergétique et optimisation économique d'un système de production éolien et photovoltaïque couplé au réseau et associé à un accumulateur ", ,(2002) PhD thesis, l'École Normale Supérieure de Cachan, France.

[3] Babarit, A., Clément, A. H., Gilloteaux, J.C. Optimisation and Time-Domain Simulation of the SEAREV Wave Energy Converter. in Proc. OMAE Conference 2005 .

[4] Duclos, G., Clément, A. H., Debusschere, V., Robin, G. Proceedings of SeaTechWeek Conf. Brest (FRANCE); 2004. 